\title{
A new technique to produce electricity using renewable energy
}

\author{
E. A. Tantawy \\ Faculty of Science, Alexandria University, Egypt
}

\begin{abstract}
A new technique is hereby introduced to produce electricity using the heat of the asphalt on roads. The aim is to benefit from the heat of the roadway to produce electricity in order to use it in road lighting. A direct way to transform the heat energy into electrical energy is still under research, so in this study an indirect way is proposed. The design consists of a close cycle with three stages. Producing electricity from the heat of the asphalt is a new technique, which is hereby called heat-electricity using methyl format (HEMF).

Keywords: heat-electricity using methyl format (HEMF), asphalt, dynamo, electrical energy, renewable energy, new energy sources, heat energy.
\end{abstract}

\section{Introduction}

Scientists have always been seeking new ways of producing electrical energy due to its importance and widespread use in almost all ways of life. There are many forms of energy that can be applied to produce electricity such as solar, wind and heat [1-11]. In this work, heat energy is being used. It was observed that the asphalt temperature on the roadway can be very high especially in many countries in the summer and this can be a source of heat to produce electricity that can be used for road lightning. One possibility is to find a direct generation technique based on that heat energy but such methods are still under research. The material used in those cases is known as thermoelectric and uses the temperature differences to drive electrons. The displaced electrons create a voltage that can be used in turn to power other devices; such as a battery. This has a conversion efficiency of about 15\%; double that of one of the most well-known thermoelectric devices. Physicists have toyed with ways to convert heat into electricity directly for some time. Such materials have found niche 
applications i.e. the Curiosity rover trundling about on the surface of Mars, for example, uses a thermoelectric material to turn heat from its plutonium power source into electricity. This does not mean that those materials have reached an adequate degree of reliability. NASA has been looking for similar materials for future space missions, but the agency is not yet convinced that they are ready for primetime $[12,13]$. The research presented in this paper considers instead the indirect generation of electricity from heat. The basic idea is to use the heat energy to apply it to produce steam, which is used to convert mechanical into electrical energy as in a turbine. The system (HEMF) is divided into three parts explained in detail in section 2. The first part is the choice of the right substance that will be turned into steam. Methyl format has been selected in the study due to its low boiling point and high steam pressure. A detailed explanation of methyl format production and properties is given in this paper. After that, the high-pressure steam produced is applied to generate rotational motion. Next, the steam is condensed to close the cycle and turn back to liquid. The rotational motion is applied to a dynamo that produces electricity. This electricity can be used to light the roadway to reduce the use of conventional electricity.

\section{Experimental section}

\subsection{Material and method}

\subsubsection{Methyl-format: composition}

$\mathrm{HCOOH}+\mathrm{CH}_{3} \rightarrow \mathrm{HCOOCH}_{3}+\mathrm{H}_{2} \mathrm{O}:$ Mix $50 \mathrm{~mL}$ methanol and $(37.7 \mathrm{~mL}, 1$ mol) formic acid together in a flask. Add 2 drops of concentrated $\mathrm{H}_{2} \mathrm{SO}_{4}$ and reflux the reaction mixture for three hours. The distillation system is set up and the temperature is adjusted to $32^{\circ} \mathrm{C}$ to collect methyl format $(53.7 \mathrm{gm}$, $55.1 \mathrm{~mL}, 89.5 \%$ ) yield. M.p.: $100^{\circ} \mathrm{C}$, B.p.: $32-34^{\circ} \mathrm{C}$ [14-17], density: 0.974 $\mathrm{g} / \mathrm{cm}^{3}$ at $20^{\circ} \mathrm{C}$, vapor pressure: $226.91 \mathrm{kPa}\left(20^{\circ} \mathrm{C}\right)$.

\subsubsection{Tubes}

Methyl format flows through tubes which are heated in the asphalt in order to turn it into steam. The tubes are made of copper metal, as this material does not react with the methyl format. The tubes end in a valve to increase the pressure of the steam which is then directed to a fan. The diameter of the tubes is $10 \mathrm{~mm}$ and their length is three meters in this case. They are laid out as in figure 1.

\subsubsection{Dynamo}

A bicycle dynamo is used in order to turn the rotational motion into electricity. Model: 4PA 6V-3W as shown in Figure 2.

\subsubsection{Heat sink}

HEMF system is a closed loop so the steam needs to be turned back into liquid, which requires the methyl format steam to condense using a heat sink. The heat sink is made of aluminium alloys. Its dimensions are $8 \mathrm{~cm} \times 6.8 \mathrm{~cm} \times 3.2 \mathrm{~cm}$ as shown in Figure 3. The heat sink is very suitable to condense the methyl format 
by letting the steam go through the sheeted surface, which extracts the heat of the steam to the surrounding mechanism turning the methyl format into liquid again. The heat sink surface is painted with copper to avoid corrosion problems.

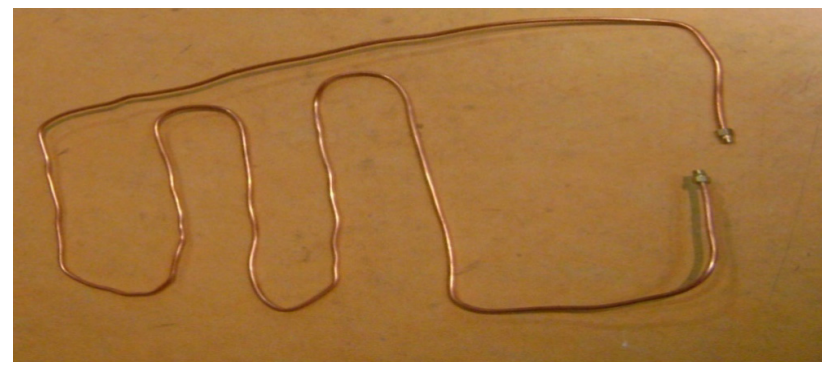

Figure 1: $\quad$ The shape of the copper tubes.

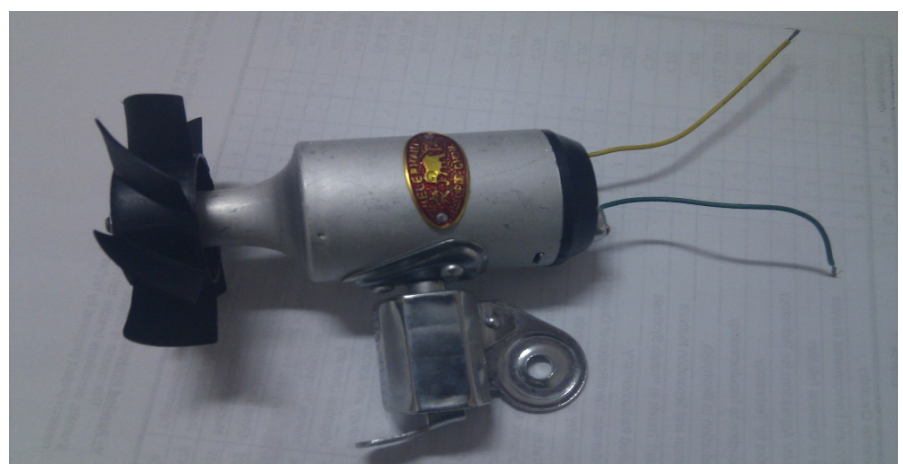

Figure 2: $\quad$ The bicycle dynamo (Model: 4PA 6V-3W).

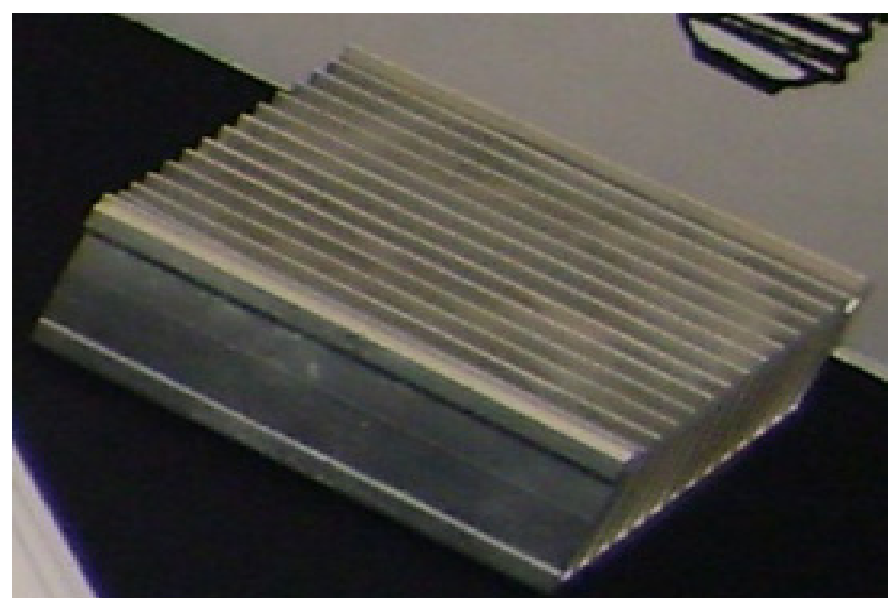

Figure 3: $\quad$ Shape of the heat sink. 


\section{Results and discussion}

The HEMF system is divided into three parts. The first part is the heat extraction, the second part is the steam generation and the last part is condensation. First stage consists of turning methyl format into steam. The second uses the highpressure steam to produce rotational motion, which is applied to a dynamo to produce electricity. The third stage condenses the steam into liquid and in this way the cycle closes.

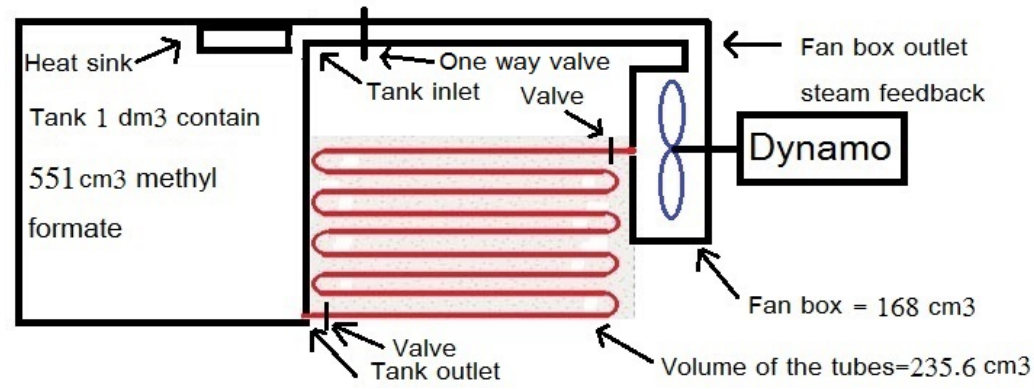

Figure 4: Design of Heat-Electricity using the Methyl Format (HEMF) system.

\subsection{First stage}

This contains a reservoir of the methyl format connected to a tube system. The pipeline system is located under the asphalt layer to extract heat. The steam is the output that will enter the second stage. A feedback comes from the third stage to the first stage directly by the returning liquid. This closed cycle is cost efficient. The first stage is the basis of the system. The pipelines flow is controlled by a valve to regulate the motion of the liquid and steam. The reason for using the methyl format is its low boiling point $\geq 32^{\circ} \mathrm{C}$, its high vapour pressure $=226.91$ $\mathrm{kPa}\left(\right.$ at $20^{\circ} \mathrm{C}$ ), zero ozone depletion potential and $<25$ global warming potential. Copper tubes are used, because according to the electrochemical series the copper tube will not react with methyl format. The copper tubes are curved as shown in figure 1 and are connected to a valve at the beginning of the tube, which controls the flow of the liquid. Moreover, at the end of the tube a second valve controls the flow of the steam. In the copper tubes, there is a steam pressure sensor to determine the pressure and open the second valve automatically to allow the steam to enter the turbine generator.

\subsection{Second stage}

This stage focuses on using the high-pressure steam to produce rotational motion. This motion occurs by pointing the steam to a fan. This fan is connected to the dynamo. When the steam is directed to the fan, it rotates the fan and the rotation motion forces it to return to stage one through the cooling part. The turbines will be sited on the road side. 


\subsection{Third stage}

This stage considers the condensation process of the steam to turn it again into liquid. The condenser is comparatively simple because the boiling point of the methyl format is very low. The steam condensed by the heat sink gives $95.7 \%$ efficiency.

\subsection{Results}

Using this system, the vapor pressure of $551 \mathrm{~mL}(10 \mathrm{~mol})$ methyl format in the tank was $226.91 \mathrm{kPa}$ at $20^{\circ} \mathrm{C}$. Methyl format was allowed to pass through a tube $3 \mathrm{~m}$ length and $10 \mathrm{~mm}$ diameter in. After heating the tubes to $50^{\circ} \mathrm{C}$, the initial vapor pressure of methyl format was $250.143 \mathrm{kPa}$ (Table 1, eqn. (1)), which produced output electricity equal to $6 \mathrm{~V}, 3 \mathrm{~W}$, and $0.5 \mathrm{~A}$.

Table 1: Relation between pressure and temperature at constant volume.

\begin{tabular}{|l|l|}
\hline Temperature & Pressure \\
\hline $293 \mathrm{~K}$ & $226.91 \mathrm{kPa}$ \\
\hline $323 \mathrm{~K}$ & $250.143 \mathrm{kPa}$ \\
\hline
\end{tabular}

The following gas law equation governs the process;

$$
\frac{P 1 V 1}{T 1}=\frac{P 2 V 2}{T 2}
$$

Increasing the pressure of methyl format by delaying the opening of the second valve, which controls the flow of the steam, for 5 min leads to an increase in the electric current. The current produced in this case was 0.67 A. A 10 min delay in opening the second valve caused an additional increase in current that became $1 \mathrm{~A}$, as illustrated in figure 5 .

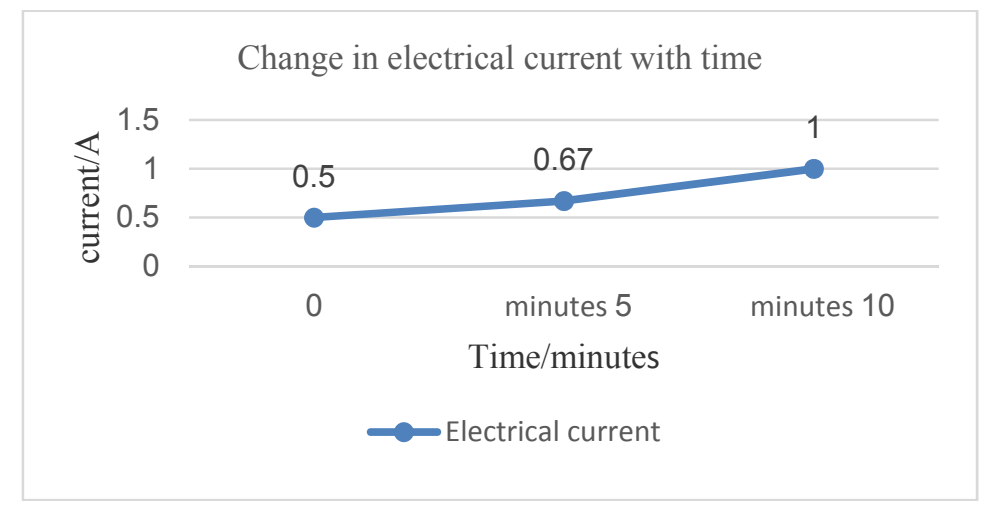

Figure 5: Increase in electrical current with valve opening times. 


\section{Conclusion}

A current was generated using the designed system. The steam was condensed by the heat sink giving $95.7 \%$ efficiency. The increase of the delay to open the valve to let the steam flow through the copper tubes increased the pressure leading to a rise in the electrical current produced.

Further investigations are being carried out to improve the system.

\section{Acknowledgements}

The author would like to thank Prof. Sherine Nabil Khattab, Faculty of Science, Alexandria University, and Eng/Ola Hassan, Faculty of Engineering, Alexandria University for their support and advice. The author is also grateful to the anonymous reviewers whose invaluable comments helped to improve the quality of this paper.

\section{References}

[1] International Energy Agency. Energy Balance for World 2009, http://www.iea.org/stats/balancetable.asp?COUNTRY_CODE=29.

[2] Central Intelligence Agency (CIA). World Factbook website, https://www.cia.gov/library/publications/the-world-factbook/geos/xx.html.

[3] Rahaman, I., Toha, Z.R. \& Ibrahim, I.B., Waste to Energy conversion: scope and procedure for meeting the next generation energy challenges. Proc. of the Global Engineering, Science and Technology Conference, Dhaka, Bangladesh, 2012.

[4] Moomaw, W., Burgherr, P., Heath, G., Lenzen, M., Nyboer, J. \& Verbruggen, A., Methodology, Cambridge University Press, Cambridge, United Kingdom \& New York, USA. Volume 11, pp. 10, 2011. http://srren.ipcc-wg3.de/report/IPCC_SRREN_Annex_II.pdf.

[5] U.S Department of Energy, New World Record Achieved in Solar Cell Technology, http://energy.gov/articles/new-world-record-achieved-solarcell-technology.

[6] Ministère de l'Écologie, du Développement durable et de l'Énergie, http://www.statistiques.developpement-durable.gouv.fr.

[7] U.S Department of Energy, Energy Efficiency and Renewable Energy, http://apps1.eere.energy.gov/news/news_detail.cfm/news_id=6490.

[8] Richards, B.S., Schäfer, A.I., Renewable Energy Powered Water Treatment Systems, Elsevier, 2009.

[9] Hull, J., Percent of Renewable Energy Produced per Country Map, 2012: https://sge.lclark.edu/2012/09/20/percent-of-renewable-energy-producedper-country-map/.

[10] United Nations Environment Program Rigid and Flexible Foams Technical Options Committee 2006 Assessment report, http://ozone.unep.org/teap/Reports/FTOC/ftoc_assessment_report06.pdf. 
[11] Bao, Y., Jiang, D., Tian L., \& Gong J., Laboratory Testing of Piezoelectric Bridge Transducers for Asphalt Pavement Energy Harvesting, Trans Tech publications, Switzerland, Vol. 492, pp. 172-175, 2012.

[12] Slashdot, http://science.slashdot.org/story/12/09/19/2132200/materialbreaks-record-for-turning-heat-into-electricity.

Nature journal, http://www.nature.com/nature/journal/v489/n7416/full/ nature 11439.html.

[13] Droz, B., Travail de Diplôme de l'école d'ingénieurs et d'architecte de Fribourg (filière de chimie), 2008.

[14] Roch, M., Travail de Bachelor de l'école d'ingénieurs et d'architecte de Fribourg (filière de chimie), 2010.

[15] Naef, O., Roch, M. \& Chappuis, T., Reaction Screening Using a Microreactor, CHIMIA, Vol. 64, pp. 889-819, 2010.

[16] National institute of standard and technology, web book, http://webbook.nist.gov/cgi/cbook.cgi?ID=107-31-3\&Units=SI\&cMS=on.

[17] ChemicalBook, http://www.chemicalbook.com/ChemicalProductProperty_ EN_CB9106448.htm. 